\title{
Exploring gaps in positive solitude perceptions: older adults vs. gerontology professionals
}

\author{
Sharon Ost-Mor, (1) Yuval Palgi, (1) and Dikla Segel-Karpas (1) \\ Department of Gerontology, University of Haifa, Haifa, Israel
}

ABSTRACT

Objectives: The aim of this study was to explore old persons' experiences of positive solitude (PS) and the gaps between their experience and professional caregivers' perceptions of older adults' experiences of PS. Moreover, we attempt to understand the basic mechanism that may explain these gaps.

Design: A qualitative method was used.

Participants: Fourty-one older adults (aged 65-103 years) and 2 groups of professionals: 16 occupational therapists with a specialization in gerontology and 41 gerontology graduate students from other occupations.

Measurement: Four open-ended questions about PS were asked. The older adults described their views on PS and experiences during solitude. The two caregiver groups, who are familiar with older adults, answered the questions twice, referring once to themselves and once to older adults in general.

Results: A. Gaps exist between old peoples' and caregivers' perceptions and experience of PS. B. The caregivers believe that older adults cannot easily enjoy PS. C. Caregivers believe that there are certain preconditions for older adults' experience of PS. D. Differences in attitude toward older adults between the caregiver groups were found.

Conclusions: Although old people occasionally prefer PS, culture and age bias may prevent caregivers from accepting older adults' need for PS. Practical implications include the need to raise awareness of age bias among caregiving staff, in particular regarding their acceptance of older adults' PS experiences. This may improve the staff's willingness to enable older adults to experience PS without interruption.

Key words: positive solitude, professional care givers, occupational therapists, gerontology, ageism

\section{Introduction}

"Solitude" describes both positive and negative aspects of "alone" situations; however, it is mostly compared to the negative aspects, such as loneliness or social isolation (Coplan and Bowker, 2013; Larson, 1990; Long et al., 2003). Others, such as Thomas and Azmitia (2014) and Lay et al. (2018), refer to time alone as time that may be filled with negative and positive emotions or experience. Merton (1999) defined the ability to experience solitude as a precondition for personhood and loving authentic contact with oneself and others. Moustakas (1972) divided existential loneliness into loneliness of solitude, which is a peaceful, harmonic state

Correspondence should be addressed to: Sharon Ost-Mor, Ph.D. Candidate, Department of Gerontology, Faculty of Social Welfare and Health Sciences, University of Haifa, 199 Aba Khoushy Ave., Mount Carmel, Haifa 3498838, Israel. Tel: 972-50-7370506; Fax: 9724 8240573. Email: petelmor@netvision .net.il. Received 01 Apr 2020; revision requested 26 Apr 2020; revised version received 08 Aug 2020; accepted 31 Aug 2020. First published online 06 Nov 2020 of confirmation or a positive encounter with oneself, and the loneliness of a broken life, which leads to painful crisis. Larson's (1990) definition of solitude as the objective condition of being alone and Burgers' (1995) definition of solitude as the absence of social interaction correspond to the comparison of solitude to loneliness.

As such, solitude may also be perceived as distressing, in which case a person might tend to avoid it (Detrixhe et al., 2014). In order to facilitate the distinction between desired and undesired solitude, we chose to probe the positive aspects of being alone. According to the literature and our previous study (Ost-Mor et al., 2020), positive solitude (PS) refers to the choice to dedicate time to a meaningful and enjoyable activity or experience conducted by oneself. This activity/experience may be of any chosen type and may take place in the presence of others (or not) but without significant interactions with them. Experiencing PS favorably affects one's quality of life and is beneficial across the life span in general, 
and in older adulthood in particular (Long and Averill, 2003).

Lay et al. (2020) found that people aged 65 years and older seek and enjoy PS. Nevertheless, older adults' desire for PS is often delegitimized by society as well as by professional caregivers (PCGs) (Palacios-Ceña et al., 2016). Older adults who live at home or in long-term care facilities are often dependent on PCGs in many ways. Because of this dependency, they may not be able to fulfill their desire for PS, as PCGs may wrongly interpret PS as reflecting loneliness or lack of interest in social engagements. PCGs might also delegitimize PS for several reasons; for example, they may rely on the medical model and activity theories, which stress the duty of PCGs to encourage engagement in activities (Kielhofner and Burke, 1980) as an "antidote" for situations that are interpreted as "being alone." PCGs are also obliged to follow policies regarding seniors' participation in some activities during their free time. An additional reason may be staff susceptibility to burnout syndrome, which may lead to a lack of empathy (Moss et al., 2016) and possibly result in an inability to handle their patients' special requests, such as being allowed to experience PS instead of being involved in the usual activities offered to old people. Moreover, as a result of burnout and/or for other reasons, PCGs may hold an ageist attitude toward the old people for whom they care (Ben-Harush et al., 2017) and therefore are unable to identify the need for PS. Hence, despite its benefits, they may not support seniors' PS, as they may think seniors are unable to enjoy time spent by themselves.

\section{PS benefits and preconditions in older adulthood}

Although in the literature, solitude and beneficial solitude are commonly referred to interchangeably, we address PS as a stand-alone concept. We do so, because "alone" situations are undesired and have negative outcomes such as health deterioration (Detrixhe et al., 2014; Larson et al., 1982; Long and Averill, 2003).

PS may be used as a way of coping with and resolving loneliness (Rokach and Brock, 1998). It also provides certain benefits: PS helps the person experiencing it feel free for self-exploration and free from social constraints without feeling threatened (Tinsley et al., 1985) and bestows a sense of having freedom of choice (Long et al., 2003). PS allows freedom from daily burdens and decision-making, which facilitates stress reduction and helps restore well-being (Lay et al., 2018). Moreover, PS leads to introspection and self-regulation and enables creativity (Nicole, 2005). Older adults who prefer PS balance well the need for sociability and the need for
PS (Thomas, 2017). Although these benefits are mostly psychological in nature, there are physiological and affective benefits as well, such as regulation of immune system activity (Miller et al., 2007; Pauly et al., 2016) and facilitating executive functions such as decision-making, generalization, processing new information, and emotional regulation (Frodl and O'Keane, 2013). Notwithstanding the benefits, a person may need certain preconditions in order to experience PS.

Evidence of the preconditions required for the experience of PS is insufficient, and most research has been conducted among younger people or adolescents. However, whether in adolescence or adulthood, most researchers have found the volition or choice component to be a requisite for PS (Lay et al., 2018; Nguyen et al., 2018; Pauly et al., 2016). Other authors have mentioned environmental settings, such as being outdoors (Long et al., 2003) or in a quiet place (Nicole, 2005). Additional components were found in our previous research (Mor et al., in press) and included environmental settings, such as place or time. Participants also mentioned that although they occasionally prefer solitary experiences, their solitude is not incompatible with good social relationships, which is consistent with the results of previous research (Bergland et al., 2016; Nicole, 2005). Not much is known about older adults' PS preconditions and experience. Existing research includes Toyoshima and Sato (2019), who found that older people adapt better to their diminishing social network when they opt for (positive) solitude; Larson et al. (1985), who found that solitude in old age brings a greater sense of control and greater interiority; Lay (2018), who showed that in old age there were no associations between being in solitude and feeling lonely; and Lay et al. (2020), who reported that $86 \%$ of solitude-seeking was voluntary at old age. However, while their inquiry was aimed at finding a relationship between social relations or solitude-seeking as a precondition for (positive) solitude, our study was not aimed at any specific precondition. Rather, we asked seniors about their experience. Moreover, as even less is known about their PCGs' understanding of it, the current study questions were aimed at exploring how both older adults and their PCGs experience PS and PS preconditions.

\section{Method}

\section{Study design}

This is one of two studies (Ost-Mor et al., 2020) derived from the same database. The research was designed as a phenomenological interpretive study, focusing on the importance and understanding 
(Denzin and Lincoln, 2000; Moran, 2000) of PS among old persons and gerontology caregivers. Several response methods were used: some of the informants answered the questionnaires in writing, while others were interviewed and their comments were written and reread by the interviewers. This enabled people with disabilities to participate orally in the research. Participants were asked to sign an informed consent form. The study was approved by the authors' University Ethics Committee (IRB no. 049/19).

\section{Sample}

The study subjects included a convenience sample of 98 participants comprising 41 old persons who were recruited by trained interviewers in their surroundings (e.g. neighborhoods and large workplaces), 16 gerontology occupational therapists (GOTs) who were recruited in a professional course they were attending, and 41 gerontology graduate students (GGSs) who were interviewed during the semester. Of the 41 old participants, 22 ( 8 men and 14 women) were aged 65-84 years (young-old) and 19 ( 11 men and 8 women) were aged $85-102$ years (old-old). The two former groups (aged 18-65 years) were divided into three age groups: 29 participants ( 7 men and 22 women) aged 18-40 years, 22 participants ( 3 men and 19 women) aged 41-64 years, and 6 women aged 65-67 years.

The proportion of men and women among the old group was almost equal, although the gender proportion among the students was different (for further information, see Table 1). Exclusion criteria were cognitive impairment and inability to understand conceptually and refer to the concept of PS (according to participants' report of cognitive status change and interviewers' impression). In a few cases, participants' answers were incompatible with the basic concept of PS. Since all participants reported intact cognitive ability, we could only assume that in these cases some minor inability (either conceptual, cognitive, or cultural) to comprehend a theoretical and abstract concept was involved. Out of 102 participants who agreed to participate, 4 were excluded for these reasons, and therefore the final sample consisted of 98 participants $^{1,2}$ (In the Results section, each GOT's number is followed by the letter " $t$ " (e.g. P. 2t). GGTs' numbers are followed by "g," and older adults' numbers have no following letter. In addition, the year of birth is marked with the letter $b$. followed by the year (b. 1930), (Study subjects were partially drawn from a former study).

\section{Data collection tool}

A four-item PS interview guide was created for the purpose of this study. The questionnaire was
Table 1. Participant characteristics by age group

\begin{tabular}{|c|c|c|c|}
\hline & MEN & WOMEN & TOTAL \\
\hline \multicolumn{4}{|l|}{ Occupational therapists } \\
\hline $18-40$ & 3 & 1 & 4 \\
\hline $41-64$ & 1 & 6 & 7 \\
\hline $65+$ & & 5 & 5 \\
\hline \multicolumn{4}{|c|}{ Gerontology graduate students } \\
\hline $18-40$ & 4 & 21 & 25 \\
\hline $41-64$ & 2 & 13 & 15 \\
\hline $65+$ & & 1 & 1 \\
\hline \multicolumn{4}{|l|}{ Old laypeople } \\
\hline 65-84 (young-old) & 8 & 14 & 22 \\
\hline $85+($ old-old $)$ & 11 & 8 & 19 \\
\hline
\end{tabular}

semi-structured with open-ended questions. The first part explained to the participants the basic ideas regarding the construct of PS.

The second part contained the following openended items: 1. Can being by oneself be a positive or agreeable experience? 2. Please write a few sentences about how being by oneself can be a positive experience. 3. Can you recall a situation in which you felt that being by yourself was a positive experience? Please describe this. 4. Please try to describe the most important attribute of PS. The GOT and GGS groups were given an additional task: "Please think about old people. Answer the following items regarding older adults."

The questionnaire concluded with a demographic section that included year of birth, gender, marital status, educational attainments, work status, health status, and economic status (for further information please, see Table 2). It took the participants 45-60 minutes to answer the questions.

\section{Procedure}

Both GOT and GGS participants answered the questionnaires first with reference to themselves and then with reference to the old people they recalled. The older participants answered the questionnaire once, about themselves. The interviews were conducted in Hebrew.

\section{Data analysis}

Data analysis stages: 1A. First, all participants' descriptions were entered verbatim into an Excel table and numbered. 1B. The information was read, reread, and reflected upon. 1C. It was sorted and assembled according to similarities in ideas and descriptions that were found in the texts. 1D. The information was arranged in lists and subdivided in two ways: first, according to participant groups (i.e. GGSs, GOTs, and older adults) and then by age groups. Hence, we used a four-stage 
Table 2. Participant demographics

\begin{tabular}{|c|c|c|c|c|c|c|c|c|c|c|c|c|c|c|}
\hline \multirow{3}{*}{ Age } & \multicolumn{4}{|c|}{ SENIORS $\mathrm{N}=41$} & \multicolumn{5}{|c|}{$\begin{array}{l}\text { GERONTOLOGY OCCUPATIONAL THERAPISTS } \\
\text { (GOT) } \mathrm{N}=16\end{array}$} & \multicolumn{5}{|c|}{$\begin{array}{l}\text { GERONTOLOGY GRADUATE STUDENTS (GGT) } \\
\qquad \mathrm{N}=41\end{array}$} \\
\hline & & & & & & & & & & & & & & \\
\hline & $\begin{array}{c}65-84 \mathrm{M} \\
(\mathrm{N}=8)\end{array}$ & $\begin{array}{l}65-84 \mathrm{~F} \\
(\mathrm{~N}=14)\end{array}$ & $\begin{array}{c}85+M \\
(N=11)\end{array}$ & $\begin{array}{l}85+F \\
(N=8)\end{array}$ & $\begin{array}{c}18-40 \mathrm{M} \\
(\mathrm{N}=3)\end{array}$ & $\begin{array}{c}18-40 \mathrm{~F} \\
(\mathrm{~N}=1)\end{array}$ & $\begin{array}{c}41-65 \mathrm{M} \\
(\mathrm{N}=1)\end{array}$ & $\begin{array}{c}41-65 \mathrm{~F} \\
(\mathrm{~N}=6)\end{array}$ & $\begin{array}{l}65+F \\
(N=5)\end{array}$ & $\begin{array}{c}18-40 \mathrm{M} \\
(\mathrm{N}=4)\end{array}$ & $\begin{array}{l}18-40 \mathrm{~F} \\
(\mathrm{~N}=21)\end{array}$ & $\begin{array}{c}41-65 \mathrm{M} \\
(\mathrm{N}=2)\end{array}$ & $\begin{array}{l}41-65 \mathrm{~F} \\
(\mathrm{~N}=13)\end{array}$ & $\begin{array}{l}65+F \\
(N=1)\end{array}$ \\
\hline \multicolumn{15}{|l|}{ Ethnicity } \\
\hline 1. Jews & 5 & 12 & 8 & 6 & & & 1 & & 5 & 3 & 8 & 2 & 12 & 1 \\
\hline 2. Druze & & & 1 & & & & & & & & & & & \\
\hline 3. Muslim & 2 & 1 & 2 & 1 & 1 & 1 & & 6 & & & 10 & & 1 & \\
\hline 4. Christian & 1 & & & 1 & & & & & & 1 & 3 & & & \\
\hline 5. Bedouin & & 1 & & & 2 & & & & & & & & & \\
\hline \multicolumn{15}{|l|}{ Religiousness } \\
\hline 1. Secular & 5 & 10 & 7 & 5 & 1 & & & 6 & 4 & 2 & 8 & 1 & 8 & 1 \\
\hline 2. Traditional & 3 & 2 & 1 & 1 & 2 & 1 & 1 & & 1 & 1 & 8 & & 4 & \\
\hline 3. Religious & & 1 & 3 & 2 & & & & & & 1 & 5 & 1 & 1 & \\
\hline 4. Orthodox & & 1 & & & & & & & & & & & & \\
\hline \multicolumn{15}{|l|}{ Marital status } \\
\hline 1. Bachelor & 1 & 1 & 5 & 1 & 2 & & & & 1 & 1 & 10 & & 3 & \\
\hline 2. Married & 6 & 6 & & 2 & 1 & 1 & 1 & 5 & 1 & 2 & 9 & 2 & 10 & 1 \\
\hline 3. Separate/divorced & 1 & 3 & & & & & & & 2 & 1 & 2 & & & \\
\hline 4. Widowed & & 4 & 6 & 5 & & & & 1 & 1 & & & & & \\
\hline \multicolumn{15}{|l|}{ Education } \\
\hline 0. None & & & 2 & 1 & & & & & & & & & & \\
\hline 1. Elementary & & 3 & 1 & 2 & & & & & & & & & & \\
\hline 2. Partial high school & & 2 & 2 & 2 & & & & & & & & & & \\
\hline 3. Full high school & 1 & 1 & 1 & & & & & & & & & & & \\
\hline 4. College & 1 & 3 & 5 & & & & & & & & & & & \\
\hline 5. University & 6 & 5 & & 3 & 3 & 1 & 1 & 6 & 5 & 4 & 21 & 2 & 13 & 1 \\
\hline \multicolumn{15}{|l|}{ Work status } \\
\hline 1. Yes & 3 & 5 & 2 & & 3 & 1 & 1 & 6 & 5 & 4 & 19 & 2 & 12 & 1 \\
\hline 2. No & 5 & 9 & 9 & 8 & & & & & & & 2 & & 1 & \\
\hline \multicolumn{15}{|l|}{ Health status } \\
\hline 1. Poor & & 1 & 2 & 1 & & & & & & & & & & \\
\hline 2. Not so good & 2 & 2 & 6 & 5 & & & & & & & & & & \\
\hline 3. Pretty good & 1 & 3 & 1 & 2 & & & & & & & & & & \\
\hline 4. Good & 3 & 8 & 1 & & & & & 2 & 4 & 2 & 11 & 1 & 9 & 1 \\
\hline 5. Excellent & 2 & & 1 & & 3 & 1 & 1 & 4 & 1 & 2 & 10 & 1 & 4 & \\
\hline
\end{tabular}

5. Bedouin

1. Secular

. Traditiona

65-84 M 65-84 F

$+M$

$+\mathrm{F}$ $=3) \quad(\mathrm{N}=1) \quad(\mathrm{N}=1)$

$\mathrm{N}=6)$

$+\mathrm{F}$
$\mathrm{N}=5)$

$\mathrm{N}=4)$

$\mathrm{N}=21$

$(\mathrm{N}=2)$

$\mathrm{N}=13$ )

$\mathrm{N}=1)$

4. Orthodox

2. Married

Separate/divorced

1. Elementary

. Partial high schoo

4. College

University 


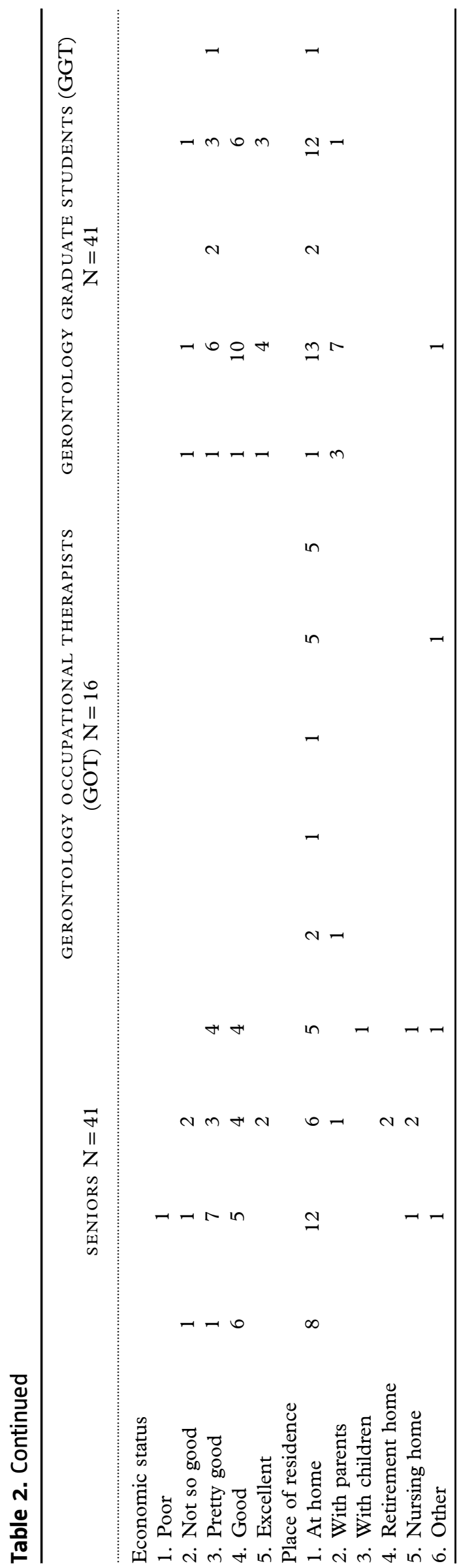

analysis (Zhung and Wildemuth, 2009) in the first step of analysis. The next step constituted cross-case analyses (Bigby, 2015), which enabled 2A.: the identification of core themes and $2 \mathrm{~B}$. the derivation of the analytical categories. 2C. Each theme was named according to the category's common narrative. ${ }^{3}$ When these stages were complete, we 2D. compared the groups. Following Carminati's model (2018), which enables a wider perspective of the outcomes, we used generalization to address our question about the differences between the preconditions for PS according to the GOT and GGS groups and older adults. Generalization involves creating larger categories, which include most cases of the same nature. $2 \mathrm{E}$. The categories were rearranged according to three identified themes: 1. Differences in PS activities between the three groups. 2. Differences in PS preconditions or settings between the three groups. 3. Ageist articulation prevalence in the groups. Further detailed categories and content analysis is described in our first paper (Mor et al., in press). 2F. Finally, we examined the compatibility of the participants' reports and the categories. If a high compatibility was found, no further action was taken; in case of disagreement, the authors held discussions and further in-depth inquiry, and decisions were made by consensus (According to our former research, core themes (volition, meaning, and outcome) are essential preconditions for the definition of PS: all three have to be met in order to define PS. However, the seven categories are independent of one another; people may experience one or more types of PS. Please note all categories were drawn from a previous study (under review)).

When all the stages were completed, the analysis enabled us to identify the disparities between the groups regarding older adult's PS.

\section{Results}

\section{PS experience}

Our previous study (Ost-Mor et al., 2020) revealed seven PS categories: A. Quietness, meaning experiencing PS as a quiet time or feeling that PS results in quietness or a peaceful state of mind. B. Experience in nature or traveling abroad. C. Recreation, hobbies, and routines. D. Escapism (as in imagining or mind wandering). E. Facilitation of achievements. F. Control of stress or thoughts. G. Spiritual or religious experience. Unlike our former study, which was aimed at understanding the PS phenomenon and differences in PS perceptions according to age, the current study focused on comparing older adults' perceptions of PS to their caregivers' perceptions of older adults' PS and 
on understanding the differences between the caregivers' groups.

\section{Older adults' and professionals' attitudes toward the PS experience and activities}

Three of the categories were similarly described by GGSs, GOTs, and old participants. All groups preferred to quietness category as described by P. 40, b. 1930, (similarly to the professional caregivers): "I enter my private space, feeling quietness and satisfaction... or after the grandchildren are here, they are so noisy... I just wait till they leave and lie down in bed, quietly... You see, I love them very much, but I need my quietness." GGS, P. 5g, b. 1991: "I enjoy my private space, I feel comfortable while away from external stimuli, from people who wish to pour their negativity onto me, and far from everyday commitments. I recharge my spirit and soul with energy." The descriptions have similar meaning. An examination of participants' descriptions for categories B and C reveal the same similarities. Regarding experience away or abroad, and recreation, hobbies, and routines, P. 5, b. 1947, says "I love taking a walk and not talking to anybody, it makes me feel so good, and it is pleasant ... sometimes I walk on the beach and it is relaxing." P. 19g, b. 1991, sums it up briefly: "Being without my cell phone in nature or by the beach ... is my positive experience." The differences between professionals and older adults in this category were only in the distance from home where they enjoyed nature: professionals traveled abroad while older adults preferred being in locations close to home. This difference can be explained by personal preferences. As for recreation, we found many activities that both PCGs and older adults enjoy equally: reading, exercising, dancing, and so forth.

Four other categories were mentioned mainly by the professionals: escapism, facilitating achievements, control of stress or thoughts, and spiritual or religious experience. No older adult mentioned these categories as a PS activity, although some mentioned past experience as such. However, only one participant, P. 32, b. 1931, mentioned religious activity: "When I am by myself, I communicate with God, pray to God to clean all my sins. I hate dependency and so I pray and beg God: don't let me suffer, I pray that I will die easily and comfortably, with no pain, no agony, no dependency.”

\section{Professionals' attitude toward older adults' PS experience and activities}

PS is perceived by old people as an enriching experience. They reported activities such as exercising for triathlons, fishing, lighting a bonfire and cooking coffee, enjoying art, thinking of past experiences, and so forth. However, our results show that professionals think differently about older persons' PS. Seven (P. 5g, 11g, 12g, 15g, 19g, 22g, and 24g, b. 1982-1991) of the 41 GGSs negatively answered our question of whether solitude might be a positive experience in old age. Some simply said "No," while the response of others resembled that of P. $15 \mathrm{~g}$ who replied "No, an old person in late life loves and wants to be with others," or that of P. $11 \mathrm{~g}$ who explained "No, because old people need help, either mental, social, or in $A D L$... Unlike young people who can handle various situations and manage alone, old people cannot!' None of the GOT group answered the question negatively. They all answered that PS is welcome among older adults, and a few added that it is as important in old age as at any other age, and it depends on the old person's personal preferences.

PCGs also referred to older adults' PS activities. While the older persons described activities similar to those described by the comparison groups, the latter gave the following examples: GOTs referred mainly to quiet activities, such as being away from others or in the (nursing home) room (P. 3t, P. 9t, P. $15 \mathrm{t}$ ), being protected from the outside world (P. 6t), coloring mandalas (P. 10t, P. 11t), talking about their memories, or looking at photo albums (P. 12t). GGSs also mentioned calm indoors activities such as writing and praying. Of the 57 professionals, only 3 thought old people might enjoy PS activities outdoors, such as sitting in the garden or walking in a park.

\section{Preconditions for PS}

Preconditions, as described by the participants, are a bit different. Older adults stressed that they enjoy PS because there is no outside interference and it provides positive feelings. They did not mention any specific preconditions for experiencing PS. Unlike the older adults themselves, PCGs thought older adults need certain preconditions.

GOTs expressed multiple preconditions: "If the person is cognitively well" (P. 3t); (P. 4t); "If he has a rich inner world, and doesn't need external support" (P. 7t); "When his physical needs are met: if he is clean ... satisfied, in a good emotional state" (P. 8t); "As long as it (PS) doesn't cut him off from daily routines and functions" (P. 9t); "If an old person is at home alone, he might not enjoy being alone, but if he is in an institution he might enjoy PS as an escape from all the external stimuli" (P. 11t); "if he is in a positive atmosphere" (P. 12t).

GGSs' range of preconditions was also wide: "If they (old people) were surrounded by lots of people all day long, they might prefer PS" (P. 2g); "If they are still busy people or in charge of something which requires a lot of energy, or live in a big family with many grandchildren, they might need to be by themselves" (P. 4g); "Only if 
they are active, free of illness or of health conditions which might limit them and if they don't need any social support" "If they have a support system" (P. 27g); and "If they feel personal well-being, if their health status, cognitive status, and mental and personal status are good ... the more the old person is able to enjoy PS" (P. 40g).

All the above statements may be categorized into the following classes: well-being (including health, cognition, mental, physical, and emotional wellbeing), environmental influences, personal abilities (or disabilities), attitude toward PS, past experience in general, and PS experience in particular. Nevertheless, we stress that old people (including those confined to a wheelchair or suffering a chronic illness) mentioned only one precondition: environmental influences, meaning they needed time, space, or no interference in order to experience PS.

Notwithstanding, we found an additional attribute of GOTs' and GGSs' attitude toward older adults. On the one hand, within the GOT group, we found a compassionate attitude toward old people: "... We maintain his quality of life, respect the old man and his desire to be in PS" (P. 1t); "PS is the same for everybody, young and old alike. It is as essential for old people as it is for me" (P. 9t); and "We have to respect their choice, their past habits in a non-judgmental way... Being in PS provides a sense of power and connection [to oneself]" (P. 7t). On the other hand, within the GGS group, we found other statements such as: "Unlike in their youth, in the present the old persons are not as busy as before... They have done their share and so they are bored" (P. 3g); "Only a few of them can really enjoy PS. I think most of them feel loneliness" (P. 6g); "In old age there are no preconditions for PS because old people always miss their family or want to be with family or a caregiver. So, PS is the same as loneliness" (P. 11g); "They have many negative feelings which disturb them" (P. 24g); "They would do things that are mainly connected to their deteriorating skills and physical inability and hope others won't pay attention to their deterioration" (P. 34g); "The ability to feel positive when by oneself is acquired during one's life and is hard to develop in old age" (P. 36g); and "When old people meet their miserable inner self, they are unable to accept themselves as old, sick, helpless people after the young healthy people they once were. They are unable to self-connect due to fear of the unknown future" (P. $5 \mathrm{~g})$. These statements represent ageist perceptions, which will be discussed in the next section.

\section{Discussion}

The current research was aimed at exploring possible gaps between old peoples' experience of PS and the perceptions of gerontology professionals regarding this experience. This is an extremely important issue since old people, especially those in a long-term facility, may need PS to gain a sense of control and freedom as part of their quality of life. This need may not be met, as some are dependent on caregivers who may be age-biased (Bodner et al., 2018; Loretto and White, 2006; Moss et al., 2016) and hence cannot see the value of PS for older people.

Similarities were found in three out of seven PS categories (PS as quietness, being in nature or abroad, and PS recreation, hobbies, and routines) as was found previously (Lay et al., 2018; Long and Averill, 2003). The other four categories (escapism, spiritual or religious experience, control of stress or thoughts, and facilitating achievements) characterized mainly the GOT and GGT groups, which consisted of younger adults. Another gap was found in GGSs and GOTs' belief that old people would be able to enjoy PS activities only under certain circumstances. These disparities may be explained by the different social roles, resources, and coping strategies that characterize different age groups (Strough and Keener, 2014). Moreover, younger people may be occupied by thoughts of their life, escape from daily burdens, and controlling stress (Lay et al., 2018; Thomas and Azmitia, 2014), while old people face other life situations and challenges and understand differently the nature of PS. Yet, when exploring the PS environment, both groups preferred to experience it in nature, while old people reported that they prefer being closer to home. This can be explained by the mechanism of health preferences in old age (Naik et al., 2016), meaning old people may prefer an activity that matches their energy levels or physical abilities and/or disabilities.

Gaps were also revealed between the professional groups. While GOTs expressed belief in old peoples' ability to enjoy PS and encouraged it, or at least accepted it as they accepted their own PS, 23 out of 41 GGSs found it more difficult to believe that old persons would enjoy PS or voluntarily choose it. One explanation may lie in education. Both are health professions and yet they focus on different experiences or issues according to the syllabus (Davys, 2008; Gray and Walker, 2015). While it is possible that both occupations focus on illness and physical or mental disabilities in old age, occupational therapists (OTs) are more exposed to the functional aspects of older adults and to activity analysis (Keilhofner and Burke, 1980), which may influence their overall comprehension of older adults' PS. Another explanation may lie in former experiences with older adults and professional education. Giles et al. (2002) found that OT practitioners and their students were more positively age biased than other health professionals. The GGSs 
who participated in the current study were less positive and more ageist, perhaps because they were still in the process of studying, unlike the GOTs, who had already gained work experience with older adults.

Two more reasons for denying older adults' PS may be as follows: first, caregivers may address PS as a continuing situation, rather than as an episode or several episodes during a given time, and second, they may misunderstand PS, that is, they may relate to it as negative alone situations instead of treating it as a volitional, stand-alone phenomenon.

Another explication may be related to culture. Although this explication will not be thoroughly discussed, we consider it worthwhile to mention. Considering the scarcity of literature about professionals' attitude toward older adults' PS in the cultural context, we can only speculate that culture plays a role in building certain beliefs, which may be influenced by ageism or cultural beliefs about older adults' PS, as was previously found (Azeiza and Kroytero, 2010; Bergman et al., 2012). Moreover, there may be a confounding combination of profession and culture, which at this moment we do not have the tools to measure.

All the above explanations cannot sufficiently clarify either the number of preconditions professionals have regarding older adults' PS or the GGSs' quotes indicating ageism. A possible mechanism that may be involved here is ageism. Healthcare providers may be more susceptible to ageist attitudes because of their exposure to the most vulnerable older adults (Liu et al., 2013). Ageism might be expressed in many forms: negative ageism (the assumption that most old people feel lonely); social ageism (the assumption that old people have exhausted all the ways of being useful to society and are therefore bored); explicit conscious ageism (thinking that old people have a "miserable inner self"); or implicit unaware ageism (thinking that an old person will not be able to acquire a new skill) (Ageism, 2019; Ayalon and Tesch-Romer, 2017; Ben Natan et al., 2010). Ageism is a complex domain that includes cognitive, behavioral, and emotional manifestations (Iversen et al., 2009). It may have a devastating effect on old peoples' well-being (Nelson, 2005) and by proxy effect distort the understanding of older adults' ability to enjoy PS. Lack of awareness of PS may lead to interference with older adults' desire for PS and their activities (Palacios-Ceña et al., 2016). Positive ageism may limit one's understanding of the heterogeneity among the older population and hinder meeting the needs of older persons (Giles et al., 2002).

The findings illustrate crucial gaps between the way old people report their PS experience and the way their caregivers think of this experience. Specifically, GGSs believed that it is unlikely that older adults can choose and enjoy the PS experience.

\section{Research limitations}

The current study referred to two groups that differ in terms of age and occupation. These differences may confound the results: we cannot specify whether the described gaps were due to age, life experience, life stage, or occupation. Moreover, some participants were in the first semester of their first academic year and therefore had not yet been exposed to topics such as PS and ageism. On the one hand, we suppose that this may have a positive influence in that they could freely express their thoughts and ideas. On the other hand, we may suspect that the GOT group members were sufficiently experienced to be aware of their answers. Either way, we did not expect an ageist attitude, since our aim was not to explore this motif. In the current study, the participants connected ageism to seniors' PS. Another limitation is the generalization of the outcomes, which is considered unorthodox in a qualitative study. Hence, we recommend further research.

\section{Future research}

In light of our findings, caregivers' attitudes toward PS should be further investigated. In addition, the ageist attitude of students in the care professions (such as social workers, physiotherapists, and others) should be studied further. Older adults' attitude toward PS is an unfamiliar field that also requires further inquiry, and the newly developed PS scale (Palgi et al., under review) could be used in a quantitative study as a measuring tool for older adults' PS. Further quantitative research is required in order to refine the outcomes of the current study. Moreover, interventions based on caregivers' observations on and analysis of older adults' PS experiences may be developed based on this research.

\section{Summary and theoretical and practical implications}

By exploring PS perception gaps between seniors and their caregivers, we provide gerontology caregivers, as well as old people and others, with new knowledge which may reduce the vagueness concerning PS and shed light on the importance of the PS experience among older adults. Moreover, it opens an opportunity to explore the PS phenomenon further. The exploration of PS as a volitional, stand-alone phenomenon is a necessity in a rapidly aging society.

The recently developed PS measuring tool could be used when one is not sure about older adults' PS preference. According to the literature, ageist attitudes should be addressed in several ways. Contact with older adults prior to entering physiotherapy and 
occupational therapy education was found to benefit students and reduce their ageism bias (Abaraogu and Norman, 2018). Interprofessional gerontology classes and group activities and projects have been recommended (Gray and Walker, 2015), as well as increasing caregivers and students' awareness by training, identifying, and preventing ageism bias (Roughan, 1993). However, since there is a gap between theoretical knowledge about ageism and personal perceptions that are sometimes rooted in social differences, old persons' caregivers may explore their own perceptions and attend to possible age bias as a result of reading this paper.

Moreover, marking PS as a stand-alone phenomenon, presenting a new PS definition, and pointing out the differences between seniors and their caregivers regarding PS are all new to the current literature. Hence, this paper opens a new horizon of PS research and legitimizes the experience of PS in all ages, and especially in old age.

\section{Conflict of interest}

The authors declare that they have no conflict of interest.

\section{Description of authors' roles}

Prof. Yuval Palgi and Dr. Dikla Segel-Karpas advised and supervised research planning. They improved the data collection tool and supervised the data collecting processing, as well as the writing of the paper. Sharon Ost-Mor planned the research, conducted the study, processed the data and wrote the paper.

\section{References}

Abaraogu, U. O. and Norman, K. E. (2018). Do physiotherapy students demonstrate ageist attitude? A scoping review of literature. Physical $\&$ Occupational Therapy in Geriatrics, 36, 72-89. https://doi.org/10.1080/ 02703181.2018.1440040

Ageism. (2019) World Health Organization. Available at: https://www.who.int/ageing/ageism/en/

Ayalon, L. and Tesch-Römer, C. (2017). Taking a closer look at ageism: self- and other-directed ageist attitudes and discrimination. European fournal of Ageing, $14,1-4$.

Azeiza, F. and Kroytero, T. (2010). Changes in old person' status in the Arab society. In: I. Brick and A. Lowenstein (Eds.), The elderly and the family. Multi-generational aspects of ageing (Vol 13, pp. 75-90). Eshel, Jerusalem.

Ben-Harush, A. et al. (2017). Ageism among physicians, nurses, and social workers: findings from a qualitative study. European fournal of Ageing, 14(1), 39-48.
Ben Natan, M., Lowenstein A. and Eisikovits, Z. (2010). Psycho-social factors affecting elders' maltreatment in long-term care facilities. International Nursing Review, 57(1), 113-120. https://doi.org/10.1111/j.1466-7657.2009 $.00771 . x$

Bergland, A. M. G., Tveit, B. and Gonzalez, M. T. (2016). Experiences of older men living alone: a qualitative study. Issues in Mental Health Nursing, 37(2), 113-120.

Bergman, Y. S., Bodner, E. and Cohen-Fridel, S. (2012). Cross-cultural ageism: ageism and attitudes toward aging among Jews and Arabs in Israel. International Psychogeriatrics, 25(1) 6-15. https://doi.org/10.1017/ S1041610212001548

Bigby, C. (2015). Preparing manuscripts that report qualitative research: avoiding common pitfalls and illegitimate questions. Australian Social Work, 68(3), 384-391. https://doi.org/10.1080/0312407X.2015.1035663

Bodner, E., Palgi, Y. and Wyman, M. F. (2018). Ageism in mental health assessment and treatment of older adults. In: L. Ayalon and C. Tesch-Romer (Eds.), Contemporary perspectives on ageism 19 (pp. 241-262). Switzerland: Springer Open. https://doi.org/10.1007/978-3-319-73820-8

Burger, J. M. (1995). Individual differences in preference for solitude. Fournal of Research in Personality, 29(1), 85-108. https://doi.org/10.1006/jrpe.1995.1005

Carminati, L. (2018). Generalizability in qualitative research: a tale of two traditions. Qualitative Health Research, 28(13), 2094-2101. https://doi.org/10.1177/ 1049732318788379

Coplan, R. J. and Bowker, J. C. (2013). The handbook of solitude: Psychological perspectives on social isolation, social withdrawal, and being alone. Hoboken, NJ: John Wiley \& Sons.

Davys, D. (2008) Ageism within occupational therapy? British Fournal of Occupational Therapy, 71(2), 72-74. https:// doi.org/10.1177/030802260807100207

Denzin, N. K. and Lincoln, Y. S. (Eds.) (2000). Handbook of qualitative study. Thousand Oaks, CA: Sage Publications.

Detrixhe, J. J., Samstag, L. W., Penn, L. S. and Wong, P. S. (2014). A lonely idea: solitude's separation from psychological research and theory. Contemporary Psychoanalysis, 50(3), 310-331. https://doi.org/10.1080/ 00107530.2014 .897853

Frodl, T. and O'Keane, V. (2013). How does the brain deal with cumulative stress? A review with focus on developmental stress, HPA axis function and hippocampal structure in humans. Neurobiology of Disease, 52, 24-37. https://doi.org/10.1016/j.nbd.2012.03.012

Giles, L. C., Paterson, J. E., Butler, S. J. and Stewart, J. J. (2002). Ageism among health professionals: a comparison of clinical educators and students in physical and occupational therapy. Physical E Occupational Therapy in Geriatrics, 21(2), 15-26. https://doi.org/10.1080/ J148v21n02_02

Gray, D. L. and Walker, B. A. (2015). The effect of an interprofessional gerontology courses on students' knowledge and interest. Physical \& Occupational Therapy in Geriatrics, 33(2), 103-117. https://doi.org/10.3109/ 02703181.2015.1006349

Iversen, T. N., Larsen, L. and Solem, P. E. (2009). A conceptual analysis of ageism. Nordic Psychology, 61(3), 4-22. https://doi.org/10.1027/1901-2276.61.3.4 
Kielhofner, G. and Burke, J. P. (1980). A model of human occupation. Part 1: Conceptual framework and content. American fournal of Occupational Therapy, 34, 572-581. https://doi.org/10.5014/ajot.34.9.572

Larson, R. (1990). The solitary side of life: An examination of the time people spend alone from childhood to old age. Developmental Review, 10(2), 155-183. https://doi.org/10 .1016/0273-2297(90)90008-R

Larson, R., Csikszentmihalyi, M. and Graef, R. (1982). Time alone in daily experience: loneliness or renewal. In: L. A. Peplau and D. Perlman (Eds.), Loneliness: $a$ sourcebook of current theory, research, and therapy (pp. 40-53) New York: Wiley. https://doi.org/10.3928/0279-369519840601-09

Larson, R., Zuzanek, J. and Mannell, R. (1985). Being alone versus being with people: Disengagement in the daily experience of older adults. Fournal of Gerontology, 40(3), 375-381. https://doi.org/10.1093/geronj/40.3.375

Lay, C. J. (2018). Alone but not lonely? distinct types, antecedents, and correlates of older and younger adults' daily life solitude experiences in two cultural contexts. (Unpublished doctoral dissertation). The University of British Columbia. Vancouver. https://open.library.ubc.ca/ cIRcle/collections/ubctheses/24/items/1.0368723

Lay, C. J., Pauly, T., Graf, P., Biesanz, J. C. and Hoppmann, C. A. (2018). By myself and liking it? Predictors of distinct types of solitude experiences in daily life. Fournal of Personality, 87(3), 633-647. https://doi.org/10 .1111 /jopy. 12421

Lay, C. J., Pauly, T., Graf, P., Mahmood, A. and Hoppmann, C. A. (2020). Choosing solitude: age differences in situational and affective correlates of solitude-seeking in midlife and older adulthood. Fournal of Gerontology, Psychological Science, 75(3), 483-493. https:// doi.org/10.1093/geronb/gby/044

Liu, Y. E., Norman, I. J. and While, A. E. (2013). Nurses' attitudes towards older people: a systematic review. International fournal of Nursing Studies, 50(9), 1271-1282. https://doi.org/10.1016/j.ijnurstu.2012.11.021

Long, C. R. and Averill, J. R. (2003). Solitude: an exploration of benefits of being alone. Fournal for the Theory of Social Behavior, 33(1), 21-44. https://doi.org/10.1111/ 1468-5914.00204

Long, C. R., Seburn, M., Averill, J. R., \& More, T. A. (2003). Solitude experiences: varieties settings and individual differences. Personality and Social Psychology Bulletin, 29(5), 578-583. https://doi.org/10.1177/ 0146167203029005003

Loretto, W. and White, P. (2006). Employers' attitude, practice and policies towards older workers. Human Resource Management Fournal, 16(3), 313-330. https://doi.org/10 $.1111 / \mathrm{j} .1748-8583.2006 .00013 . x$

Merton, T. (1999). Thoughts in solitude. New York: Farrar, Straus and Giroux.

Miller, G. E., Chen, E. and Zhou, E. S. (2007). If it goes up, must it come down? Chronic stress and hypothalamicpituitary-adrenocortical axis in humans. Psychological Bulletin, 133, 25-45. https://doi.org/10.1037/0033-2909 .133 .1 .25

Moran, D. (2000). Introduction to phenomenology. London: Routledge.
Moss, M., Good, V. S., Gozal, D., Kleinpell, R. and Sessler, C. N. (2016). An official critical care societies collaborative statement: burnout syndrome in critical care health care professionals: a call for action. American fournal of Critical Care, 25(4), 368-376. https://doi.org/10.4037/ ajcc2016133

Moustakas, C.E. (1972). Loneliness and love. Prentice-Hall.

Naik, A. D., Martin, L. A., Moye, J. and Karel, M. J. (2016). Health values and treatment goals of older, multimorbid adults facing life-threatening illness. Fournal of American Geriatric Society, 64(3), 625-631. https://doi .org/10.1111/jgs. 14027

Nelson, T. D. (2005). Ageism: prejudice against our feared future self. Fournal of Social Issues, 61(2), 207-221. https:// doi.org/10.1111/j.1540-4560.2005.00402.x

Nguyen, T. T., Ryan, R. M. and Deci, E. L. (2018). Solitude as an approach to affective self-regulation. Personality and Social Psychology Bulletin, 44, 92-106. https://doi.org/10.1177/0146167217733073

Nicole, C. C. (2005). Self-determined motivation for solitude and relationship: scale development and validation (Unpublished doctoral dissertation). South Illinois University, Carbondale, IL.

Ost-Mor, S., Palgi, Y. and Segel-Karpas, D. (2020). The definition and categories of positive solitude: Older and younger adults' perspectives on spending time by themselves. International fournal of Aging and Human Development, 1-20. https://doi.org/10.1177/099 1415020957379

Palacios-Ceña, D., Gómez-Calero, C., Cachón-Pérez, J. M., Velarde-García, J. F., Martínez-Piedrola, R. and Pérez-De-Heredia, M. (2016). Is the experience of meaningful activities understood in nursing homes? A qualitative study. Geriatric Nursing, 37(2), 110-115. https://doi.org/10.1016/j.gerinurse.2015.10.015

Pauly, T., Lay, J. C., Nater, U. M., Scott, S. B. and Hoppmann, C. A. (2016). How we experience being alone: age differences in affective and biological correlates of momentary solitude. Gerontology: Behavioural Science Section, 63, 55-66. https://doi.org/10.1159/000450608

Rokach, A. and Brock, H. (1998). Coping with loneliness. The Fournal of Psychology, 124(1), 39-54. https://doi.org/10 $.1080 / 00223989809599269$

Roughan, P. A. (1993). Mental health and psychiatric disorder in older women. Clinics in Geriatric Medicine, 9(1), 173-190.

Strough, J. N. and Keener, E. J. (2014). 13 goals and strategies of solving interpersonal everyday problems across the lifespan. In: P. Verhaeghen \& C. Hertzog (Eds.), The Oxford handbook of emotions, social cognition and problem solving in adulthood. New York: Oxford Library of Psychology, Oxford University Press.

Thomas, V. D. (2017). How to be alone: an investigation of solitude skills. Retrieved from UC Santa Cruz Electronic Thesis and Dissertations (ProQuest ID: Thomas_ucsc_0036E_11275).

Thomas, V. and Azmitia, M. (2014). Motivation matters: development of a short form measure of solitude for adolescents and emerging adults. Poster presented at the meeting of the Society for Research on Adolescence, Austin, TX. https://escholarship.org/uc/item/3414t2qv.pdf. 
Tinsley, H. E. D., Teaff, J. D., Colbs, S. L. and Kaufman, N. (1985). A system of classifying leisure activities in term of psychological benefits of participation reported by older persons. Fournal of Gerontology, 40(2), 172-178. https://doi.org/10.1093/ geronj/40.2.172

Toyoshima, A. and Sato, S. (2019). Examination of the effect of preference for solitude on subjective well-being and developmental change. Fournal of Adult Development, 26, 139-148. https://doi.org/10.1007/s10804018-9307-z

Zhung, Y. and Wildemuth, B. M. (2009). Qualitative analysis of content. In: B. M. Wildemuth (Ed.), Applications of social research: methods to questions in information on library science (2nd ed., pp. 318-328). Santa Barbara, CA: Libraries Unlimited. 